ISSN 1980-5098

\title{
FENOLOGIA DE ESPÉCIES NATIVAS ARBÓREAS NA REGIÃO CENTRAL DO ESTADO DO RIO GRANDE DO SUL
}

\author{
PHENOLOGY OF NATIVE TREE SPECIES IN THE CENTRAL REGION OF THE STATE \\ OF RIO GRANDE DO SUL/BRAZIL
}

\author{
Tiago Silveira Ferrera ${ }^{1}$ Taíse Maria Pelissaro ${ }^{2}$ Sônia Maria Eisinger ${ }^{3}$ Evandro Zanini Righi ${ }^{4}$ \\ Galileo Adeli Buriol ${ }^{5}$
}

\section{RESUMO}

O objetivo geral deste trabalho foi acompanhar a fenologia vegetativa e reprodutiva de 20 espécies arbóreas nativas existentes no Jardim Botânico da Universidade Federal em Santa Maria, Santa Maria - RS, associando a duração das diferentes fenofases desta comunidade vegetal com as variáveis da temperatura do ar e precipitação pluviométrica e do comprimento do dia. O trabalho foi realizado no período de agosto de 2010 a agosto de 2011. Marcaram-se, aleatoriamente, 185 árvores, com 4 a 10 indivíduos de cada espécie, nas quais foram observadas quinzenalmente as fenofases vegetativas (folhas maduras, queda foliar e brotamento) e reprodutivas (floração - botão e antese; frutificação - fruto verde/imaturo e fruto maduro). Foram utilizados dois métodos de observação: o índice de atividade fenológica (ausência/presença do evento) e o Índice de Fournier. Os valores destes índices foram submetidos à correlação de Spearman com os dados meteorológicos. Na fenologia vegetativa constatou-se que o brotamento da comunidade foi constante em todo o período de estudo, a queda foliar mais acentuada no outono e inverno e as folhas maduras com plena capacidade fotossintética tiveram picos crescentes na primavera e verão e redução no inverno de quase $50 \%$. Na fenologia reprodutiva, os maiores picos de floração aconteceram na primavera e durante o período inicial do verão e a frutificação ocorreu preferencialmente durante o verão e início do outono. As fenofases correlacionaram-se significativamente com o comprimento do dia e a temperatura do ar, e não com a precipitação pluviométrica.

Palavras-chave: fenofases; bioclimatologia vegetal; ecologia vegetal.

\begin{abstract}
The general aim of this study was to monitor the vegetative and reproductive phenology of 20 native tree species existing in the Botanical Garden of the Federal University of Santa Maria, Santa Maria-RS, Brazil. This general aim was reached by associating the duration of the different phenophases of this plant community with the air temperature, rainfall and day length. The investigation was conducted from August 2010 to August 2011. A total of 185 trees were randomly selected and marked, with 4-10 individuals of each species. Among this total selected trees, vegetative phenophases (mature leaves, leaf fall and bud) and reproductive ones (flowering - bud and anthesis; fruit - unripe fruit and ripe fruit) were observed,

1 Biólogo, Dr., Pós-doutorando do Programa de Pós-Graduação em Ciência do Solo, Centro de Ciências Rurais, Universidade Federal de Santa Maria, Rua Coronel João de Deus, 600 Bairro Santa Tereza I, CEP 98015-370, Cruz Alta (RS), Brasil. tsferrera@yahoo.com.br

2 Bióloga, MSc, Professora da SEDUC-RS, Centro de Ciências Naturais e Exatas, Universidade Federal de Santa Maria, Av. Roraima, 1000, CEP 97110-970, Santa Maria (RS), Brasil. taisepelissaro@yahoo.com.br

3 Bióloga, Dr., Professora do Departamento de Biologia, Centro de Ciências Naturais e Exatas, Universidade Federal de Santa Maria, Av. Roraima, 1000, CEP 97110-970, Santa Maria (RS), Brasil. soniame@ccne.ufsm.br

4 Agrônomo, Dr., Professor do Departamento de Fitotecnia, Centro de Ciências Rurais, Universidade Federal de Santa Maria, Av. Roraima, 1000, CEP 97110-970, Santa Maria (RS), Brasil. ezrighi@yahoo.com.br

5 Agrônomo, Dr., Professor do Programa de Pós-Graduação em Agrobiologia, Centro de Ciências Naturais e Exatas, Universidade Federal de Santa Maria, Av. Roraima, 1000, CEP 97110-970, Santa Maria (RS), Brasil. galileoburiol@yahoo.com.br
\end{abstract}

Recebido para publicação em 5/06/2014 e aceito em 15/02/2016

Ci. Fl., v. 27, n. 3, jul.-set., 2017 
fortnightly. Two methods of observation were used: the rate of phenological activity (absence / presence of the event) and the Fournier Index. The values of these indices were subjected to Spearman correlation with meteorological data. In vegetative phenology it was found that the community budding was constant throughout the study period. The sharpest leaf fall occurred in autumn and winter and the mature leaves with full photosynthetic capacity had increased peaks in spring and summer and decreased almost $50 \%$ in winter. In reproductive phenology, the highest peak of flowering occurred in spring and during the early summer and the fruiting occurred mostly during the summer and the early fall. The phenophases were significantly correlated with day length and air temperature, not with rainfall.

Keywords: phenophases; bioclimatology vegetable; plant ecology.

\section{INTRODUÇÃO}

A fenologia vegetal proporciona conhecer a dinâmica do crescimento e desenvolvimento das plantas (TALORA; MORELLATO, 2000; PASCALE; DAMARIO, 2004). As fenofases estão associadas com as variáveis climáticas e meteorológicas como radiação solar, temperatura do ar, evaporação, precipitação pluviométrica e umidade do ar, com os fatores locais como fotoperíodo e solo e, ainda, com os elementos bióticos como pragas e doenças. Desse modo, a caracterização das fenofases das diferentes espécies é importante para o estudo da dinâmica da população e da comunidade de plantas de uma determinada área e ou região (ORTOLANI; CAMARGO, 1987; MORELATTO, 2007). Estudos desse tipo existem em abundância para culturas agrícolas anuais e perenes, conforme destacam Pascale e Damario (2004), porém, há escassez de relatos na bibliografia sobre a fenologia de espécies arbóreas nativas, especialmente na Região Sul do Brasil. O conhecimento da fenologia de espécies nativas e sua resposta aos fatores climáticos são importantes para o desenvolvimento de ações para a sua preservação em áreas/condições adequadas, para projetos paisagísticos e exploração comercial (MORELATTO, 2007).

Os poucos estudos existentes nesta área da ecologia foram realizados nas regiões tropicais do Brasil, havendo grande escassez de informações nas regiões subtropicais. No estado do Rio Grande do Sul (RS), destacam-se os trabalhos de fenologia com espécies nativas arbóreas realizados por Longhi (1984), Reitz, Klein e Reis (1988), Alberti (2002), Andreis et al. (2005), Brun et al. (2007), Marchioretto, Mauhs e Budke (2007) e Athayde et al. (2009). Neles se podem evidenciar as diferenças fenológicas que ocorrem nas comunidades arbóreas, principalmente por meio do estabelecimento de relações com os fatores abióticos e, também, da sucessão dos eventos fenológicos.

Nos trabalhos de Longhi (1984) e Reitz, Klein e Reis (1988) encontra-se uma descrição qualitativa das fenofases das diferentes espécies nativas arbóreas, não mencionando valores numéricos de quantificação e intensidade das fenofases. Porém, naqueles de Alberti (2002), Andreis et al. (2005), Marchioretto, Mauhs e Budke (2007) e Athayde et al. (2009) foram utilizados métodos quantitativos de estimativa. A importância desta divisão reside no fato do aprofundamento dos estudos ecofisiológicos das espécies não ter somente dados qualitativos, mas a quantificação da intensidade das fenofases.

As determinações fenológicas das fenofases vegetativas e reprodutivas das espécies nativas do Rio Grande do Sul associadas às variações dos elementos climáticos necessitam de mais estudos. Os dados fenológicos possibilitam um melhor entendimento da dinâmica de crescimento e desenvolvimento de uma população e de uma comunidade natural ou cultivada em um determinado local ou região. Os dados fenológicos possibilitam ordenar os eventos biológicos para entender cronologicamente estes processos visando ao conhecimento das inter-relações com outras áreas das ciências. Sob esse viés, é importante que as determinações fenológicas em espécies nativas arbóreas sejam permanentes e ampliadas, principalmente naquelas que possuem perspectivas de cultivo econômico ou de recuperação de ecossistemas degradados. Isto constitui um acúmulo de conhecimento inestimável para planejamentos na área ecológica e florestal.

Portanto, o objetivo deste estudo foi associar as fenofases vegetativa e reprodutiva de 20 espécies arbóreas nativas existentes no Jardim Botânico da Universidade Federal de Santa Maria, Santa Maria - RS, com os elementos meteorológicos como a temperatura do ar, a precipitação pluviométrica e a duração astronômica do dia. 


\section{MATERIAL E MÉTODOS}

\section{Área de Estudo}

O trabalho foi realizado no Jardim Botânico da Universidade Federal de Santa Maria, UFSM,

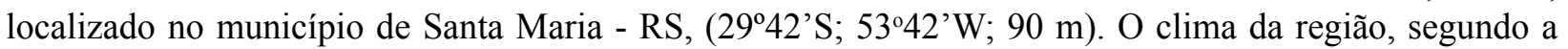
classificação de Köppen, é do tipo Cfa, subtropical, com precipitação pluviométrica bem distribuída ao longo do ano. A temperatura média anual é de $19,2^{\circ} \mathrm{C}$ e a precipitação pluvial média anual de $1712 \mathrm{~mm}$ (BURIOL et al., 2006). O local de estudo possui uma área de 13 ha, na qual estão presentes, aproximadamente, 515 espécies de plantas pertencentes a 96 famílias, principalmente angiospermas. Dentro dessa área, encontram-se trechos de vegetação herbácea, capoeiras, canteiros de plantas medicinais, árvores frutíferas, espécies ornamentais e bambuzais. Algumas áreas, principalmente próximas à via de acesso, são manejadas periodicamente com roçadora acoplada a trator, sendo uma parte manejada manualmente e o restante da área sofre interferência mínima (LEMES; RITTER; MORAIS, 2008).

Foram selecionadas 20 espécies (Tabela 1) e, para cada uma destas, marcados 4 a 10 indivíduos adultos, de forma aleatória, totalizando 185 plantas. As determinações fenológicas foram realizadas visualmente e com o auxílio de um binóculo, com periodicidade quinzenal, de agosto de 2010 a agosto de 2011, totalizando 27 observações.

As fenofases que compuseram a ficha de observação foram: fenologia reprodutiva: (1) botões florais: desde o início da formação da estrutura floral até a abertura dos botões florais; (2) antese: representada pela abertura das flores até a queda das peças florais; (3) frutos verde/imaturo: desde a formação do fruto até o amadurecimento, visualizada pela presença de frutos de coloração verde; (4) frutos maduros: frutos totalmente desenvolvidos podendo ter coloração diferenciada; e fenologia vegetativa: (5) folhas maduras: folhas com todo potencial fotossintético; (6) queda foliar: presença de folhas amarelas na copa, perda das folhas sob o vento e presença de folhas caídas sob a copa das árvores; e (7) brotamento: marcado pelo aparecimento de folhas jovens com coloração diferenciada (avermelhada ou verde-clara) (FOURNIER, 1974; GALETTI; PIZO; MORELLATO, 2006).

\section{Análise dos dados}

A análise das observações fenológicas foi realizada por dois métodos: presença/ausência da fenofase e Índice de Fournier (FOURNIER, 1974). No caso da presença/ausência da fenofase, a quantificação dos eventos fenológicos foi realizada pelo índice de atividade, que se refere ao porcentual de indivíduos que manifestaram os eventos em cada amostragem. As fenofases foram avaliadas utilizando o índice de atividade ( $\%$ de indivíduos), pelo qual se constata a presença/ausência do evento em cada indivíduo, porém, em nível populacional, torna-se um método de caráter quantitativo, indicando a porcentagem de indivíduos da população que está manifestando a fenofase (ATHAYDE et al., 2009). Com a sua utilização é possível também estimar a sincronia entre os indivíduos de uma população (BENCKE; MORELLATO, 2002).

O Índice de Fournier (FOURNIER, 1974) possibilita estimar a intensidade das fenofases e foi quantificado subjetivamente, a partir de observações visuais, atribuindo-se os valores 0 (ausência de fenofase), 1 (até 25\%), 2 (até 50\%), 3 (até 75\%) e 4 (até 100\%) de intensidade na fenofase. Os valores obtidos em campo com a utilização da escala intervalar semiquantitativa de cinco categorias ( 0 a 4$)$ permitiram estimar a porcentagem de intensidade da fenofase em cada indivíduo (BENCKE; MORELLATO, 2002).

Os dados fenológicos foram associados ao comprimento astronômico do dia e às variáveis: temperatura média diária do ar $\left({ }^{\circ} \mathrm{C}\right)$ e precipitação pluviométrica $\left(\mathrm{mm} \mathrm{d}^{-1}\right)$. Os dados meteorológicos foram obtidos na Estação Meteorológica Automática do $8^{\circ}$ Distrito de Meteorologia do Instituto Nacional de Meteorologia ( $8^{\circ}$ DISME/INMET), instalada na área do Departamento de Fitotecnia da UFSM, localizada a cerca de $1,0 \mathrm{~km}$ da área experimental (www.inmet.gov.br).

O comprimento astronômico do dia $(\mathrm{N}, \mathrm{h})$ foi calculado em função da latitude local $\left(\phi,{ }^{\circ}\right)$ e do dia Juliano (D):

$$
\delta=23,45 \operatorname{sen}[360(284+D) / 365]
$$


TABELA 1: Espécies selecionadas para as determinações fenológicas no Jardim Botânico da Universidade Federal de Santa Maria, UFSM. Santa Maria - RS, 2011.

TABLE 1: Species selected for phenological determinations in the Botanical Garden, Federal University of Santa Maria, UFSM. Santa Maria, RS, 2011.

\begin{tabular}{|c|c|c|c|}
\hline Família & Nome científico & Nome popular & N. indivíduos \\
\hline \multirow{4}{*}{ Anacardiaceae } & Lithraea molleoides (Vell.) Engler & Aroeira-brava Masculina & 10 \\
\hline & Lithraea molleoides (Vell.) Engler & Feminina & 10 \\
\hline & Schinus terebinthifolius Raddi & Aroeira-vermelha & 10 \\
\hline & Schinus terebinthifolius & Feminina & 10 \\
\hline Bignoniaceae & $\begin{array}{l}\text { Handroanthus heptaphyllus (Vell.) } \\
\text { Mattos }\end{array}$ & Ipê-roxo & 9 \\
\hline Cordiaceae & $\begin{array}{l}\text { Cordia americana (L.) Gottschling } \\
\text { \& J.S.Mill. }\end{array}$ & Guajuvira & 9 \\
\hline Euphorbiaceae & $\begin{array}{l}\text { Sebastiania commersoniana } \\
\text { (Baill.) L.B. SM. \& Downs }\end{array}$ & Branquilho & 10 \\
\hline \multirow{4}{*}{ Fabaceae } & $\begin{array}{l}\text { Albizia niopoides (Benth) Killip } \\
\text { ex }\end{array}$ & Angico-branco & 6 \\
\hline & $\begin{array}{l}\text { Enterolobium contortisiliquun } \\
\text { (Vell.) Morong }\end{array}$ & Timbauvá & 5 \\
\hline & Inga uruguensis Hook. \& Arn. & Ingá & 10 \\
\hline & $\begin{array}{l}\text { Parapiptadenia rigida (Benth.) } \\
\text { Brenan }\end{array}$ & Angico-vermelho & 8 \\
\hline Malvaceae & Luehea divaricata Mart. & Açoita-cavalo & 10 \\
\hline \multirow{2}{*}{ Myrsinaceae } & $\begin{array}{l}\text { Myrsine coriacea (Sw.) R.Br. ex } \\
\text { Roem. \& Schult. }\end{array}$ & Caporoca & 4 \\
\hline & $\begin{array}{l}\text { Myrsine coriacea (Sw.) R.Br. ex } \\
\text { Roem. \& Schult. }\end{array}$ & Feminina & 4 \\
\hline \multirow{3}{*}{ Myrtaceae } & $\begin{array}{l}\text { Blepharocalyx salicifolius (Kunth) } \\
\text { O. Berg }\end{array}$ & Murta & 6 \\
\hline & Eugenia uniflora $\mathrm{L}$. & Pitangueira & 10 \\
\hline & Myrciaria tenella (DC.) O.Berg. & Cambuí, Cambuim, Camboí & 6 \\
\hline Rosaceae & Prunus myrtifolia (L.) Urb. & Pessegueiro-do-mato & 10 \\
\hline \multirow{4}{*}{ Rutaceae } & Zanthoxylum rhoifolium Lam. & Mamica-de-cadela & 4 \\
\hline & & Masculina & \\
\hline & Zanthoxylum rhoifolium Lam. & Feminina & 4 \\
\hline & Helietta apiculata Benth. & Canela-de-veado & 4 \\
\hline Salicaceae & Casearia sylvestris $\mathrm{Sw}$. & Chá-de-bugre; Carvalhinho & 10 \\
\hline \multirow[t]{2}{*}{ Sapindaceae } & $\begin{array}{l}\text { Allophylus edulis (A. St.-Hil., } \\
\text { Cambess. \& A. Juss.) Radlk. }\end{array}$ & Chal-chal & 6 \\
\hline & Cupania vernalis Cambess. & Camboatá-vermelho & 10 \\
\hline
\end{tabular}




$$
N=2 \operatorname{acos}[-\tan (\delta) \tan (\phi)] / 15
$$

Em que $\delta$ é a declinação solar $\left(^{\circ}\right)$.

Com a utilização do software BioEstat 5.0, calculou-se a correlação de Spearman entre as variáveis meteorológicas: comprimento astronômico do dia, temperatura do ar e precipitação do ano de observação.

\section{RESULTADOS E DISCUSSÃO}

\section{Caracterização das condições meteorológicas durante o período das observações}

O comprimento do dia na latitude de $29^{\circ} 42^{\prime} 53^{\prime}$ 'S variou entre média de $13,92 \mathrm{~h}$ na segunda quinzena de dezembro e 10,09 h na segunda quinzena de junho (Figura 1a). A menor e a maior média mensal das temperaturas mínimas, durante o período experimental, foram $6,7^{\circ} \mathrm{C}$ e $21,7^{\circ} \mathrm{C}$, e das temperaturas máximas $16,0^{\circ} \mathrm{C}$ e $32,2^{\circ} \mathrm{C}$, respectivamente, nos meses de julho/2010 e janeiro/2011. Os meses com maiores totais mensais de precipitação pluviométrica foram julho $(238,3 \mathrm{~mm})$ e setembro $(244,9 \mathrm{~mm})$ de 2010 , enquanto que em outubro de 2010 e maio de 2011 ocorreram os menores totais mensais, respectivamente, 49,3 mm
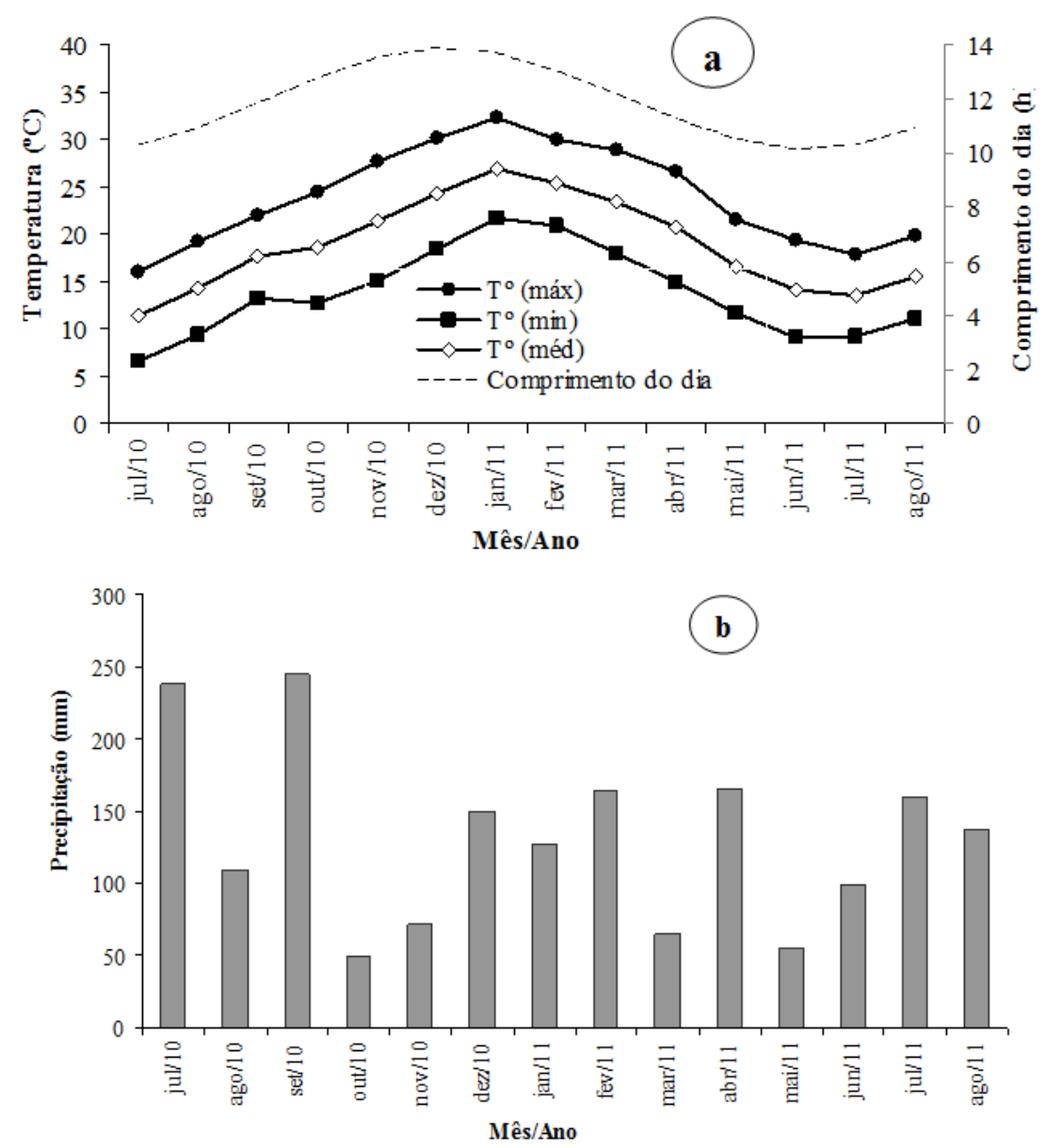

FIGURA 1: Variação mensal do comprimento astronômico do dia e das médias mensais das temperaturas máximas, médias e mínimas diárias (a); e do total mensal de precipitação, no período de julho/2010 a agosto/2011(b). Santa Maria - RS.

FIGURE 1: Fluctuation of astronomical day length and monthly average of maximum and minimum daily temperature fluctuation (a); and the total monthly rainfall for the period from July 2010 to August/2011 (b). Santa Maria, RS. 


\section{e 54,9 mm (Figura 1b).}

Comparando-se os valores observados na Figura 1 aos valores normais mensais, verifica-se que o inverno foi mais frio e o verão mais quente durante o período experimental (temperaturas mínimas e máximas médias mensais normais, respectivamente, de 9,5 e $19,2^{\circ} \mathrm{C}$ em julho e 19,1 e 30,4 em janeiro (INSTITUTO NACIONAL DE METEOROLOGIA, 1992). Quanto às precipitações pluviométricas, os valores normais mensais são $145,1 \mathrm{~mm}, 130,2 \mathrm{~mm}, 151,7 \mathrm{~mm}, 134,7 \mathrm{~mm}, 129,1 \mathrm{~mm}, 144,0 \mathrm{~mm}, 148,6$ $\mathrm{mm}, 137,4 \mathrm{~mm}, 153,6 \mathrm{~mm}, 145,9 \mathrm{~mm}, 132,2 \mathrm{~mm}, 133,5 \mathrm{~mm}$, respectivamente, de janeiro a dezembro (BURIOL et al., 2006). Comparando-os com os valores da Figura 1, constata-se que nos meses de julho, setembro e dezembro de 2010 e fevereiro, abril e julho de 2011, os valores observados foram superiores aos normais e nos meses de outubro e novembro de 2010 e março, maio e junho de 2011, foram inferiores aos normais, enquanto que nos demais meses ficaram próximos das normais. Contudo, como as precipitações pluviométricas foram regulares, pode-se inferir que, se houve deficiência hídrica, ela pode ser considerada amena, mesmo nos meses de outubro e novembro de 2010 e março de 2011, quando ocorreram baixos valores de precipitação pluviométrica $(<80 \mathrm{~mm})$, haja visto que espécies arbóreas possuem sistema radicular mais profundo, buscando água em camadas de solo mais profundas.

\section{Fenologia vegetativa}

$\mathrm{Na}$ Figura 2a observa-se que as folhas maduras estiveram presentes em todos os indivíduos avaliados do mês de outubro de 2010 até maio de 2011. Nos meses de setembro e outubro de 2010 e junho a agosto de 2011 ocorreu uma menor quantidade de indivíduos apresentando folhas maduras, entretanto, as diferenças foram pequenas considerando-se a comunidade como um todo. A queda foliar (Figura 2b) foi mais expressiva nos meses de agosto a outubro de 2010 e maio a agosto de 2011, principalmente, em consequência das espécies caducifólias totais ou parciais (Handroanthus heptaphyllus, Sebastiania commersoniana, Albizia niopoides, Enterolobium contortisiliquun, Parapiptadenia rigida, Luehea divaricata, Zanthoxylum rhoifolium e Casearia sylvestris) perderem as folhas e entrarem em dormência (Figura 2a), enquanto que o brotamento foi mais intenso nos meses de agosto 2010 e 2011.

Pelo Índice de Fournier (Figura 2b), observa-se que, nos meses de janeiro a abril de 2011, a quantidade de folhas maduras permaneceu constante, com valor próximo de 4, e nos meses de agosto a outubro de 2010 e junho a agosto de 2011, a quantidade de folhas maduras diminuiu (valores do Índice de Fournier abaixo de 3,0 ), enquanto que a queda foliar nestes meses atingiu valores próximos ou superiores a 1 . O brotamento manteve-se com um índice inferior a $1 \mathrm{em}$ praticamente todo o período de observação, porém, foi crescente de agosto a dezembro de 2010 e decrescente de março a julho de 2011. O brotamento das plantas ao longo de praticamente todo ano permitiu a renovação constante das folhas. De modo geral, verifica-se sazonalidade das fenofases da fase vegetativa, com exceção de folhas maduras, em que houve pouca variação ao longo do período de observação, assim como observado por Athayde et al. (2009) para região de Santa Maria - RS.

Conforme descrito no trabalho de Longhi (1984), a queda foliar é mais expressiva no outono e no inverno, fato também observado por Brun et al. (2007), que relataram os meses de março a junho como o grande período de desfolhamento e o início de agosto, com o advento da primavera, o período mais visível do brotamento, fenômeno que ocorre todo ano. De modo geral, os prováveis grandes indutores do brotamento foliar foram a elevação da temperatura do ar, consequência do aumento da duração astronômica do dia, e a diminuição da declinação solar, conforme Taiz e Zeiger (2013).

A caducidade foliar está correlacionada às baixas temperaturas ocorridas durante os meses de inverno e à diminuição da duração astronômica do dia (Figura 1), conforme previamente observado por Alberti (2002). A fenofase queda de folhas foi de intensidade reduzida para a maioria das espécies, com os indivíduos possuindo baixa sincronia, ocorrendo num ritmo estável durante a maior parte do ano, concordando com Marchioretto, Mauhs e Budke (2007) e Andreis et al. (2005) devido às mesmas condições climáticas.

Nos trabalhos de Alberti (2002), Andreis et al. (2005), Marchioretto, Mauhs e Budke (2007) e Athayde et al. (2009) com a fenologia vegetativa de espécies nativas do estado do RS, em geral observouse que a intensidade de ocorrência de folhas maduras ao longo de todo ano é superior aos eventos de queda 


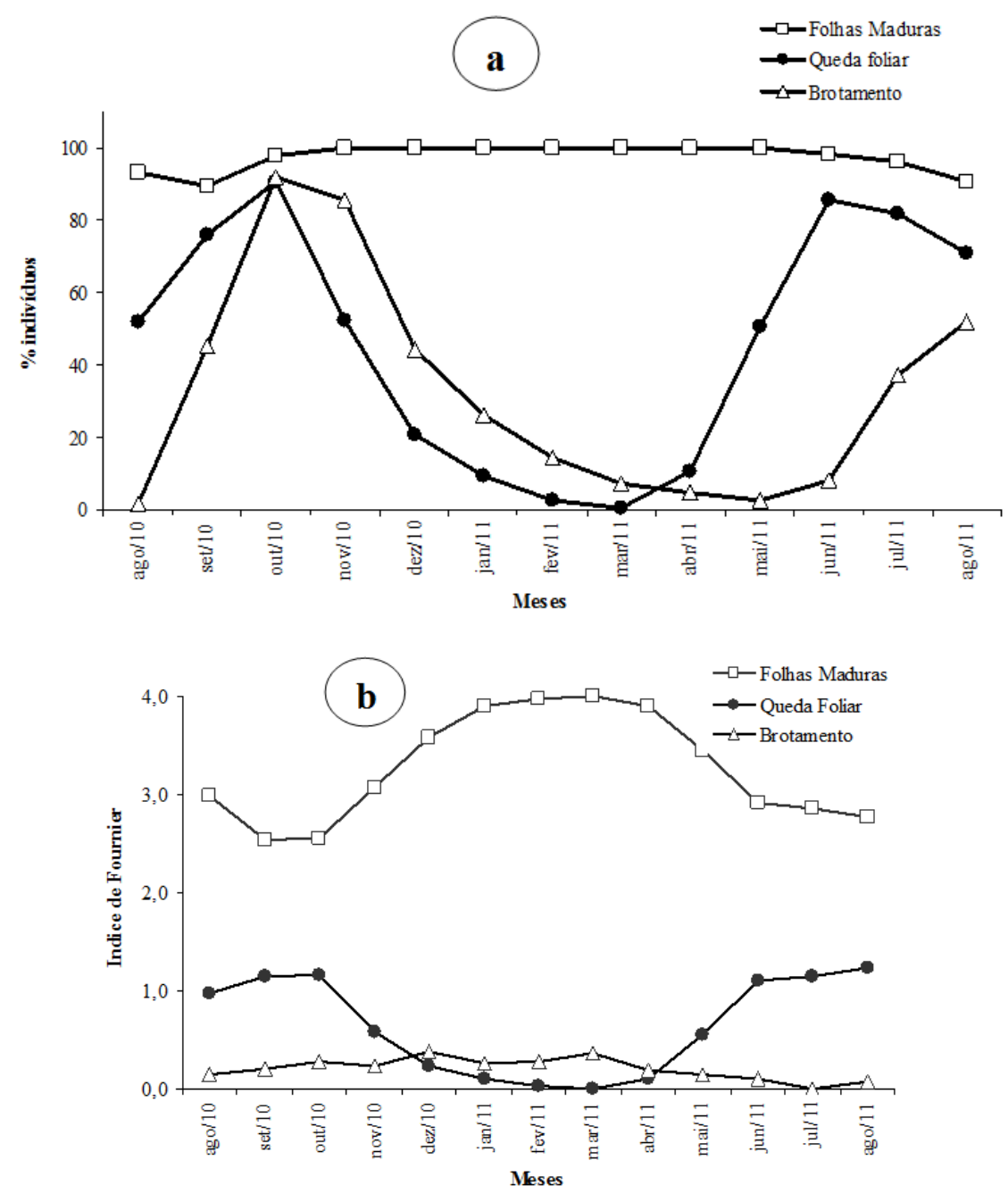

FIGURA 2: Percentual de indivíduos com presenças de: folhas maduras; queda foliar; e brotamento (a) e Índice de Fournier para fenologia vegetativa de uma amostra de 185 indivíduos de 20 espécies nativas, período de agosto de 2010 a agosto de 2011 (b), no Jardim Botânico-UFSM, Santa Maria - RS.

FIGURE 2: Percentage of individuals with precense of mature leaves, leaf fall, and budding (a) and Fournier Index for vegetative phenology of a sample of 185 individuals of 20 native species, from August 2010 to August 2011 (b), in the Botanical Garden, UFSM, Santa Maria, RS.

foliar, corroborando com os resultados obtidos nesse estudo. A queda foliar é mais expressiva nos meses do outono e inverno (Figuras 1 e 2), quando, segundo Larcher (2004), o metabolismo das plantas diminui.

\section{Fenologia reprodutiva}

Na Figura 3 constata-se que a presença dos botões florais foi mais expressiva no final do inverno e na primavera (meses de setembro a dezembro de 2010 e agosto de 2011). Nos outros meses do ano, a presença de botões florais diminuiu para cerca de 5 a $10 \%$, com exceção no mês de junho de 2011, com cerca de apenas $0,5 \%$ indivíduos do total avaliado. Na fenofase de antese (Figura 3), os maiores valores, em torno de $25 \%$, ocorreram nos meses com temperaturas do ar mais elevadas, maior intensidade de radiação solar incidente e dias mais longos (outubro de 2010 a fevereiro de 2011). No mês de julho não foi observada antese, provavelmente pela consequência de dias mais curtos, menor incidência de radiação solar 


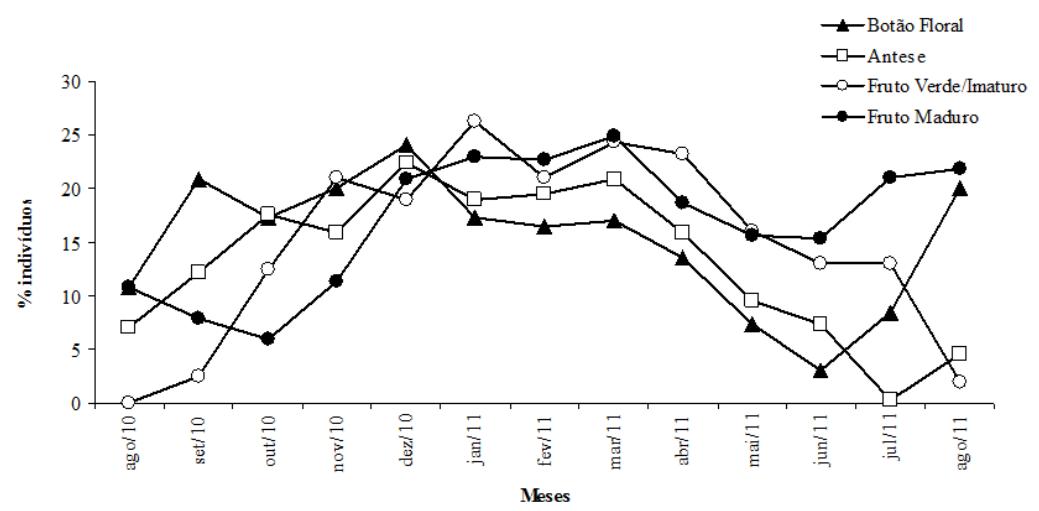

FIGURA 3: Número de indivíduos com presença de botões florais (a); antese (b); fruto imaturo/verde (c); e fruto maduro (d) de uma amostra de 185 indivíduos de 20 espécies nativas arbóreas, no período de agosto de 2010 a agosto de 2011, no Jardim Botânico-UFSM. Santa Maria - RS.

FIGURE 3: Percentage of individuals with presence of flower buds (a); anthesis (b); unripe fruit (c) and ripe fruit (d) of a sample of 185 individuals of 20 native species of trees, from August 2010 to August 2011, the Botanical Garden-UFSM. Santa Maria, RS.

e temperaturas baixas (Figura 1). Nos resultados de presença/ausência de fruto imaturos/verdes, observase que os picos foram maiores de outubro a dezembro de 2010 e janeiro, fevereiro e março de 2011 . Tanto em agosto de 2010 como de 2011, houve menor cerca de $0,5 \%$ frutificação verde. Contudo, para os frutos maduros, os maiores picos ocorreram em dezembro de 2010 a março de 2011, havendo frutos maduros ao longo de todo ano e em diferentes estágios de maturação.

Com relação ao Índice de Fournier, observa-se na Figura 4a que os valores mais elevados para botão floral ocorreram de setembro de 2010 a março de 2011, com retomada intensa de ocorrência em agosto de 2011. Porém, a emissão de botões florais ocorreu durante o ano todo, com diminuição dos valores nos meses mais frios do ano. Na fenofase de botão floral, os maiores valores foram registrados em outubro e dezembro de 2010 e março de 2011. A intensidade de botões florais e antese, no decorrer do acompanhamento fenológico, alcançou o valor máximo de 0,4 do Índice de Fournier. Esse baixo valor se deve a estas fenofases ocorrerem em datas distintas e com intensidade distintas para as diferentes espécies.

Quanto ao Índice de Fournier para frutificação, observa-se que este também não ultrapassou o valor de 0,4 (Figura 4b). Os maiores valores para frutificação imatura/verde ocorreram nos meses de novembro de 2010 e em janeiro, março e abril de 2011. Comparando-se com a análise de ausência/presença, percebese que nos meses de agosto de 2010, não ocorreu frutificação verde. Quanto à fenofase de fruto maduro, observa-se que os valores do índice de Fournier não passaram de 0,3 que ocorreram em dezembro de 2010 e março e abril de 2011 e quanto à fenofase de fruto maduro, a maior queda ocorreu nos meses de setembro e outubro de 2010.

No trabalho realizado por Alberti (2002) foi constatado que a floração aconteceu na transição entre um período seco e chuvoso. Já Marchioretto, Mauhs e Budke (2007) observaram que todas as espécies floresceram com ritmos diferentes ao longo do ano, sendo que em setembro e outubro, houve um incremento de espécies em floração. Semelhante aos trabalhos de Athayde et al. (2009) e Andreis et al. (2005), o incremento na primavera ocorreu também com as plantas no Jardim Botânico da UFSM, no período das observações, devido ao aumento do comprimento do dia e da temperatura do ar, acima de $25^{\circ} \mathrm{C}$.

Foi constatado por Alberti (2002) que as fenofases de frutificação diferem em significância e padrão da fenofase frutos novos para alguns grupos de árvores. A frutificação apresentou menor sazonalidade em relação à floração, com indivíduos frutificando com maior regularidade ao longo do ano. Isto também ocorreu nas espécies observadas neste trabalho, em que a frutificação foi observada durante todo o ano, com pico de atividades nos meses de verão. Marchioretto, Mauhs e Budke (2007) observaram que o maior 

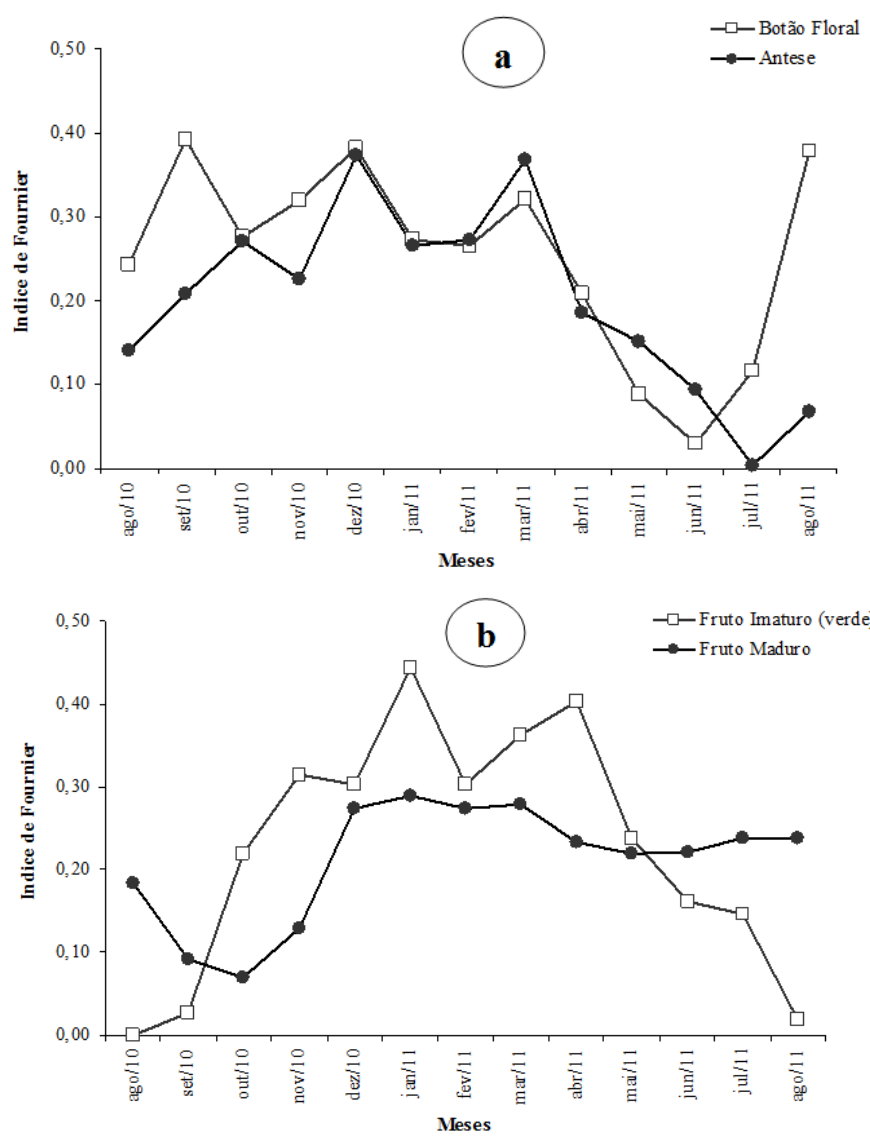

FIGURA 4: Índice de Fournier para fenologia reprodutiva, sendo (a) floração e (b) frutificação de uma amostra de 185 indivíduos de 20 espécies nativas arbóreas, período de agosto de 2010 a agosto de 2011, no Jardim Botânico - UFSM. Santa Maria - RS.

FIGURE 4: Fournier Index for reproductive phenology (a) flowering and (b) fruiting of a sample of 185 individuals of 20 native species of trees, from August 2010 to August 2011, the Botanical Garden-UFSM. Santa Maria, RS.

pico de frutificação ocorreu em novembro e dezembro, no caso frutificação imatura. Andreis et al. (2005) estudaram as fenofases em 53 espécies dentre árvores e arbustos, destas 17 frutificaram. Entretanto, no Jardim Botânico da Universidade Federal de Santa Maria - UFSM, todas as espécies contempladas no presente estudo floresceram e frutificaram.

Outros trabalhos em diferentes regiões do Brasil e até mesmo em outros países denotam a influência da precipitação sob as fenofases vegetais. Por exemplo, em fragmento florestal de São Paulo - SP, Ferraz (1999) observou que a floração ocorreu no início da estação seca com pico em setembro, sendo que a floração e a frutificação estavam dispersas por todo ano. Na floresta da Mata Atlântica em Santa Catarina, Mantovani et al. (2003) observaram que a floração é maior de outubro a janeiro; a frutificação de janeiro a março, portanto, em períodos reprodutivos diferentes aos relatados e observados na Região Sudeste. Talora e Morellato (2000), em São Paulo, constataram que as espécies arbóreas apresentaram floração mais intensa de janeiro a fevereiro, na estação chuvosa, e a frutificação, ao longo do ano, com padrão pouco sucessional.

Na floresta semidecidual, no estado do Paraná, o pico de floração ocorre na estação chuvosa (setembro-outubro), sendo maior a frutificação entre maio-junho quando diminuem as precipitações (MIKICHI; SILVA, 2001). Liesbch e Mikich (2009) estudaram a fenologia na Floresta Ombrófila Mista do Paraná e observaram que a floração ocorre em setembro-dezembro, com pico em outubro e a frutificação em dezembro-abril, com pico em fevereiro. No inverno poucas espécies florescem e frutificam. 
Em floresta estacional semidecidual em Montana, Lavras - MG foram realizadas observações fenológicas por Dias e Oliveira Filho (1996), no período de 1991-1994 os autores observaram que a floração ocorre no início da estação seca e a frutificação no final da estação chuvosa. Reys et al. (2005), que trabalharam com a mata ciliar no estado do Mato Grosso do Sul, verificaram que nesta região a floração ocorre entre a transição das estações seca e chuvosa e a frutificação correlaciona-se com a temperatura do ar e não com as precipitações pluviométricas. No cerrado, em Brasília, o florescimento ocorre ao longo do ano com novas flores entre as estações seca e chuvosa. A maturação dos frutos ocorre na estação seca para espécies com dispersão anemocórica e zoocóricas na estação chuvosa (LENZA; KLINK, 2006). Ainda, no Distrito Federal, em matas de galeria, o longo período da floração está relacionado com a precipitação pluviométrica (ANTUNES; RIBEIRO, 1999). Já, Pirani et al. (2009), no cerrado do Mato Grosso, destacaram que a floração ocorre nos meses de maior estresse hídrico e a frutificação das espécies anemocóricas também, nos meses mais secos e as espécies zoocóricas nos meses mais chuvosos. No cerrado em São Paulo, a floração ocorre no início da estação chuvosa e a frutificação no final das chuvas (BATALHA et al., 1997).

Na região da caatinga, semiárido nordestino, as espécies destacam-se por uma floração e frutificação na época de chuvas, e a frutificação de frutos secos ocorre todo ano (AMORIM et al., 2009). Barbosa et al. (1989), também na vegetação da caatinga, fizeram observações fenológicas de 1982-1986 e concluíram que a floração predominantemente ocorre no período chuvoso e a frutificação em $70 \%$ das espécies no final do mês seco. Na Bahia em Diamantina, observou-se que a floração e frutificação são fenômenos contínuos com picos nas estações chuvosas (FUNCH et al., 2002).

A floração e a frutificação com picos em agosto e outubro, no final da estação seca e frutos maduros na estação chuvosa são observadas em florestas neotropicais da Bolívia (JUSTINIANO; FREDERICKSEN, 2000). Na Colômbia, em florestas tropicais e semicaducifólias, (BORCHERT, 1994) observou-se que o aumento da radiação solar induz à floração.

Nos trabalhos realizados em outras regiões do Brasil, bem como em outros países são denotadas as diferenças do clima em relação àquele do estado do Rio Grande do Sul e suas influências nas fenofases. A associação de calor com temperatura do ar em média de $25^{\circ} \mathrm{C}$ e a boa condição hídrica favorecem o desenvolvimento das plantas em qualquer local. $O$ frio não é relatado como fator determinante nas fenofases reprodutivas, se bem que se percebe a intensidade das fenofases após o acúmulo de frio, principalmente por plantas criófilas, como observado nas plantas existentes no Jardim Botânico da UFSM.

\section{Relação entre as fenofases e variáveis meteorológicas}

Das variáveis ambientais avaliadas, apenas a temperatura do ar e a duração astronômica do dia correlacionaram-se de modo significativo com as fenofases (Tabelas 2 e 3). Para o botão floral, a correlação é maior com a duração do dia no mês em que ocorre o evento, enquanto que os eventos de antese, frutificação imatura e madura, folhas maduras e queda foliar se correlacionam com o comprimento do dia e com a temperatura do ar do mês anterior ao evento e de ocorrência do evento. No brotamento, não se observou correlação com nenhuma das variáveis abióticas em questão. O aumento do brotamento em 2010, provavelmente, deveu-se ao aumento do comprimento astronômico dos dias associado à maior intensidade de radiação solar, o que repercutiu em temperatura do ar mais elevada (Figura 1), resultando também no aumento do número de folhas em amadurecimento fotossintético. Segundo Larcher (2004), com a redução do comprimento do dia e da temperatura do ar, observa-se uma elevação da queda foliar, principalmente, nas plantas criófilas.

$\mathrm{Na}$ Tabela 3 observa-se que o Índice de Fournier se correlaciona com a temperatura do ar e comprimento do dia tanto no mês anterior ao evento quanto no mês em que ele ocorre. Entretanto, não há correlação com a frutificação madura, assim como nenhuma das fenofases se correlacionou com a precipitação pluviométrica. Resultados semelhantes foram observados por Athayde et al. (2009) e Marchioretto, Mauhs e Budke (2007). Os resultados obtidos comprovam a influência dos fatores abióticos na indução das fenofases em regiões relativamente distantes da linha do Equador, conforme relatado por Alberti (2002).

A falta de correlações significativas entre a presença/ausência das fenofases com a precipitação 
TABELA 2: Correlação de Spearman entre presença/ausência das diferentes fenofases e o comprimento do dia, temperatura do ar e precipitação pluviométrica em uma amostra de 185 indivíduos de 20 espécies nativas arbóreas, período de agosto de 2010 a agosto de 2011, no Jardim Botânico da Universidade Federal de Santa Maria-UFSM, Santa Maria - RS.

TABLE 2: Spearman correlation between the presence / absence of different phenophases and day length, air temperature and precipitation in a sample of 185 individuals of 20 native species of trees, from August 2010 to August 2011, in the Botanical Garden, Federal University of UFSMSanta Maria, Santa Maria, RS.

\begin{tabular}{lcccccc}
\hline \multirow{2}{*}{ Fenofase } & \multicolumn{3}{c}{ Temperatura } & \multicolumn{2}{c}{ Comprimento do dia } & \multicolumn{2}{c}{ Precipitação } \\
\cline { 2 - 7 } & $\begin{array}{c}\text { Mês anterior ao } \\
\text { evento }\end{array}$ & $\begin{array}{c}\text { Mês em que } \\
\text { acontece o evento }\end{array}$ & $\begin{array}{c}\text { Mês anterior ao } \\
\text { evento }\end{array}$ & $\begin{array}{c}\text { Mês em que } \\
\text { acontece o evento }\end{array}$ & $\begin{array}{c}\text { Mês anterior ao } \\
\text { evento }\end{array}$ & $\begin{array}{c}\text { Mês em que } \\
\text { acontece o } \\
\text { evento }\end{array}$ \\
\hline Botão floral & $0,0716(0,8161)$ & $0,5152(0,0715)$ & $0,3738(0,2083)$ & $0,7407(0,0038)$ & $0,0854(0,7815)$ & $0,2204(0,4693)$ \\
Antese & $0,8462 \mathrm{p}(0,0003)$ & $0,9066(<0,0001)$ & $0,9216(<0,0001)$ & $0,8226(0,0006)$ & $0,0110(0,9716)$ & $0,0440(0,8866)$ \\
Fruto imaturo & $0,8981(<0,0001)$ & $0,7493(0,0032)$ & $0,8138 \mathrm{p}(0,0007)$ & $0,5103(0,0743)$ & $0,3113(0,3005)$ & $0,0110(0,9715)$ \\
Fruto maduro & $0,8981(<0,0001)$ & $0,7493(0,0032)$ & $0,8138(0,0007)$ & $0,5103(0,0743)$ & $0,3113(0,3005)$ & $0,0110(0,9715)$ \\
Folhas maduras & $0,8721(0,0001)$ & $0,6989(0,0078)$ & $0,7985(0,0011)$ & $0,4875(0,0910)$ & $0,2389(0,4317)$ & $0,2091(0,4930)$ \\
Queda foliar & $0,7747(0,0019)$ & $0,7273(0,0050)$ & $0,7098 \mathrm{p}(0,0065)$ & $0,4677(0,1070)$ & $0,0549(0,8585)$ & $0,1484(0,6286)$ \\
Brotamento & $0,1813(0,5533)$ & $0,1264(0,6808)$ & $0,0440(0,8865)$ & $0,4072(0,1673)$ & $0,1648(0,5905)$ & $0,0055(0,9858)$ \\
\hline
\end{tabular}

Em que: Os valores entre parênteses correspondem a significância.

TABELA 3: Correlação de Spearman entre o Índice de Fournier para as diferentes fenofases e o comprimento do dia, temperatura do ar e precipitação pluviométrica em uma amostra de 185 indivíduos de 20 espécies nativas arbóreas, período de agosto de 2010 a agosto de 2011, no Jardim Botânico da Universidade Federal de Santa Maria-UFSM, Santa Maria - RS.

TABLE 3: Spearman correlation between the Fournier Index for different phenophases and day length, air temperature and precipitation in a sample of 185 individuals of 20 native species of trees, from August 2010 to August 2011 at the Botanical Garden of the University Federal de Santa Maria-UFSM, Santa Maria, RS.

\begin{tabular}{|c|c|c|c|c|c|c|}
\hline \multirow[b]{2}{*}{ Fenofase } & \multicolumn{2}{|c|}{ Temperatura } & \multicolumn{2}{|c|}{ Comprimento do dia } & \multicolumn{2}{|c|}{ Precipitação } \\
\hline & $\begin{array}{c}\text { Mês Anterior ao } \\
\text { evento* }\end{array}$ & $\begin{array}{c}\text { Mês em que } \\
\text { acontece o evento }\end{array}$ & $\begin{array}{c}\text { Mês Anterior ao } \\
\text { evento }\end{array}$ & $\begin{array}{c}\text { Mês em que } \\
\text { acontece o evento }\end{array}$ & $\begin{array}{c}\text { Mês Anterior ao } \\
\text { evento }\end{array}$ & $\begin{array}{c}\text { Mês em que } \\
\text { acontece o evento }\end{array}$ \\
\hline Botão floral & $0,0330(0,9149)$ & $0,4341(0,1382)$ & $0,2806(0,3530)$ & $0,6272(0,0217)$ & $0,0549(0,8585)$ & $0,1868(0,5411)$ \\
\hline Antese & $0,7473(0,0033)$ & $0,8736(<0,0001)$ & $0,8693(0,0001)$ & $0,8583(0,0002)$ & $0,0769(0,8028)$ & $0,1099(0,7208)$ \\
\hline Fruto imaturo & $0,8858(<0,0001)$ & $0,7895(0,0013)$ & $0,8485(0,0002)$ & $0,5893(0,0339$ & $0,2779(0,3580)$ & $0,0715(0,8164)$ \\
\hline Fruto maduro & $0,5647(0,0443)$ & $0,4793(0,0973)$ & $0,4814(0,0957)$ & $0,2690(0,3742)$ & $0,0799(0,7953)$ & $0,2204(0,4693)$ \\
\hline Folhas maduras & $0,8516(<0,0002)$ & $0,6923(0,0087)$ & $0,7455(0,0034)$ & $0,4154(0,1580)$ & $0,0714(0,8166)$ & $0,0220(0,9432)$ \\
\hline Queda foliar & $0,8736(<0,0001)$ & $0,7143(0,0061)$ & $0,7730(0,0019)$ & $0,4429(0,1295)$ & $0,1044(0,7343)$ & $0,0330(0,9149)$ \\
\hline Brotamento & $0,7473(<0,0033)$ & $0,8736(<0,0001)$ & $0,8693(0,0001)$ & $0,8583(0,0002)$ & $0,0769(0,8028)$ & $0,1099(0,7208)$ \\
\hline
\end{tabular}

Em que: Os valores entre parênteses correspondem a significância.

pluviométrica deve-se à distribuição regular das precipitações ao longo dos doze meses do ano, não ocorrendo, assim, restrição de água às plantas arbóreas. Como árvores possuem um sistema radicular pivotante, profundo e extenso, elas absorvem água de um volume de solo maior e mais profundo (LARCHER 2004; TAIZ; ZEIGUER, 2013). Em função da profundidade e extensão do sistema radicular das plantas, elas conseguem absorver água do solo o suficiente para que deficit hídricos moderados não interfiram na ocorrência das fenofases ao longo de todo o ano (MOTA, 1976; LARCHER 2004; TAIZ; ZEIGUER, 2013).

Nos fragmentos florestais, em São Paulo, as fenofases se correlacionaram com a temperatura e a 
precipitação pluviométrica (FERRAZ, 1999). Não ocorreu correlação da frutificação com a temperatura do ar e a precipitação pluviométrica, enquanto que com o brotamento e a floração a correlação com estas variáveis foi elevada (MORELLATO et al., 2000). Neste trabalho, não houve correlação significativa entre a precipitação pluviométrica e as fenofases. Na Floresta Atlântica de restinga observou-se que o brotamento correlaciona-se com a temperatura do ar e o comprimento do dia (MARQUES; OLIVEIRA, 2004). Significativa correlação com a temperatura do ar e o comprimento do dia é um indicativo da alta sazonalidade e influência da altitude e latitude que propicia baixas temperaturas e até geadas, na Floresta Ombrófila Mista no Paraná (LIESBCH; MIKICH, 2009). No cerrado do Mato Grosso a queda foliar correlaciona-se negativamente com a temperatura do ar e o comprimento do dia, mas houve significativa correlação com as precipitações pluviométricas (PIRANI et al., 2009). A correlação com o armazenamento de água no solo e índice pluviométrico foi significativa nos estudos fenológicos na Floreta Tropical na Costa Rica, já a temperatura do ar e o comprimento do dia não se correlacionam por serem constantes todo ano nas regiões próximas ao Equador (AREILH; BORCHERT, 1984; BORCHERT, 1994).

\section{CONCLUSÃO}

Em função dos resultados obtidos conclui-se que:

- na fenologia vegetativa das espécies nativas arbóreas estudadas, as folhas maduras sempre estão presentes, ocorrendo redução no período de inverno com a queda foliar, enquanto que o brotamento é constante;

- na fenologia reprodutiva, as espécies diferem muito quanto ao período e intensidade das fenofases, havendo sempre a presença de flores e frutos, sendo os picos maiores para floração na primavera e verão e para a frutificação no final do verão e no outono;

- a correlação de Spearman é significativa para o comprimento do dia e temperatura do ar e não significativa para precipitação pluviométrica.

\section{REFERÊNCIAS}

ALBERTI, L. F. Fenologia de uma Comunidade Arbórea em Santa Maria-RS. 2002. 160 f. Dissertação (Mestrado em Engenharia Florestal) - Universidade Federal de Santa Maria, Santa Maria, 2002.

AMORIM, I. L. et al. Fenologia de Espécies Lenhosas da Caatinga do Seridó, RN. Revista Árvore, Viçosa, MG, v. 33, n. 3, p. 491-499, 2009.

ANDREIS, C. et al. Estudos fenológico em três fases sucessionais de uma Floresta Estacional Decidual no município de Santa Tereza, RS, Brasil. Revista Árvore, Viçosa, MG, v. 29, n. 1, p. 55-63, 2005.

ANTUNES, N. B.; RIBEIRO, J. F. Aspectos fenológicos de seis espécies vegetais em matas de galeria do Distrito Federal. Pesquisa Agropecuária Brasileira, Brasília, v. 34, n. 9, p. 1517-1527, 1999.

ATHAYDE, E. A. et al. Fenologia de espécies arbóreas em uma floresta ribeirinha em Santa Maria, sul do Brasil. Revista Brasileira de Biociências, Porto Alegre, v. 7, n. 1, p. 43-51, 2009.

BARBOSA, D. C. A. et al. Dados fenológicos de 10 espécies arbóreas de uma área de caatinga (AlagoinhaPE). Acta Botânica Brasílica, Belo Horizonte, v. 3, n. 2, p. 109-117, 1989.

BATALHA, M. A. et al. Variações fenológicas das espécies do cerrado em Emas, Pirassununga, São Paulo. Acta Botânica Brasílica, Belo Horizonte, v. 11, n. 1, p. 61-78, 1997.

BENCKE, C. S. C.; MORELLATO, L. P. C. Comparação de dois métodos de avaliação da fenologia de plantas, sua interpretação e representação. Revista Brasileira de Botânica, São Paulo, v. 25, n. 3, p. 269-275, 2002.

BORCHERT, R. Water storage in soil or tree stems determines phenology and distribution of tropical dry forest trees. Ecology, London, v. 75, p. 1437-1449, 1994.

BRUN, F. G. K. et al. Comportamento fenológico e efeito da poda em algumas espécies empregadas na arborização do Bairro Camobi - Santa Maria, RS. Revista da Sociedade Brasileira de Arborização Urbana, Curitiba, v. 1, p. 44-63, 2007.

BURIOL, G. A. et al. Homogeneidade e estatísticas descritivas dos totais mensais e anuais de chuva de Santa Maria, Estado do Rio Grande do Sul. Revista Brasileira de Recursos Hídricos, Porto Alegre, v. 11, 
p. 89-97, 2006.

DIAS, H, C. T.; OLIVEIRA FILHO, A. T. Fenologia de quatro espécies arbóreas de uma floresta estacional semidecídua montana em Lavras, MG. Cerne, Lavras, v. 2, p. 1, p. 66-88, 1996.

FERRAZ, D. K. et al. Fenologia de árvores em fragmento de mata em São Paulo, SP. Revista Brasileira de Biologia, São Carlos, v. 59, n. 2, p. 305-317, 1999.

FOURNIER, L. A. Un método cuantitativo para la medición de características fenológicas em árboles. Turrialba, Turrialba, v. 24, p. 422-423, 1974.

FUNCH, L. S. et al. Phenology of Gallery and Montane Forest in the Chapada Diamantina, Bahia, Brazil. Biotropica, Belo Horizonte, v. 34, n. 1, p. 40-50, 2002.

GALLETI, M.; PIZO, M. A.; MORELLATO, P. C. Fenologia, frugivoria e dispersão de sementes. In: CULLEN JUNIOR, L.; RUDRAN, R.; VALLADARES-PADUA, C. Métodos e estudos em biologia da conservação e manejo da vida silvestre. 2. ed., Curitiba: Ed. Universidade Federal do Paraná, 2006. p. 395-422.

INSTITUTO NACIONAL DE METEOROLOGIA (Brasil). Normais climatológicas. Brasília: Ministério da Agricultura e do Abastecimento, 1992.

JUSTINIANO, M. J.; FREDERICKSEN, T. S. Phenology of tree species in Bolivian dry forests. Biotropica, Belo Horizonte, v. 32, p. 276-281, 2000.

LARCHER, W. Ecofisiologia vegetal. São Carlos: RiMa, 2004. 531 p.

LEMES, R.; RITTER, C. D.; MORAIS, A. B. B. Borboletas (Lepidoptera: Hesperioidea e Papilionoidea) visitantes florais no Jardim Botânico da Universidade Federal de Santa Maria, Santa Maria, RS, Brasil.

Biotemas, Florianópolis, v. 21, n. 4, p. 91-98, 2008.

LENZA, E.; KLINK, C. A. Comportamento fenológico de espécies lenhosas em um cerrado sentido restrito de Brasília, DF. Revista Brasileira de Botânica, São Paulo, v. 29, n. 4, p. 627-638, 2006.

LIEBSCH, D.; MIKICH, S. B. Fenologia reprodutiva de espécies vegetais da Floresta Ombrófila Mista do Paraná, Brasil. Revista Brasileira de Botânica, São Paulo, v. 32, n. 2, p. 375-391, 2009.

LONGHI. S. J. Fenologia de algumas espécies florestais e ornamentais. Revista do Centro de Ciências Rurais, Santa Maria, v. 14, n. 3/4, p. 231- 240, 1984.

MANTOVANI, M. et al. Fenologia reprodutiva de espécies arbóreas em uma formação secundária da Floresta Atlântica. Revista Árvore, Viçosa, MG, v. 27, n. 4, p. 451-458, 2003.

MARCHIORETTO, M. S.; MAUHS, J.; BUDKE, J. C. Fenologia de espécies arbóreas zoocóricas em uma floresta psamófila no sul do Brasil. Acta Botânica Brasílica, Belo Horizonte, v. 21, n. 1, p. 193-201, 2007. MARQUES, M. C. M.; OLIVEIRA, P. E. A M. Fenologia de espécies do dossel e do sub-bosque de duas Florestas de Restinga na Ilha do Mel, sul do Brasil. Revista Brasileira de Botânica, São Paulo, v. 27, n. 4, p. 713-723, 2004.

MIKICH, S. B.; SILVA, S. M. Composição Florística e Fenologia das Espécies Zoocóricas de Remanescentes de Floresta Estacional Semideciduas no Centro-Oeste do Paraná, Brasil. Acta Botânica Brasílica, Belo Horizonte, v. 15, n. 1, p. 89-113, 2001.

MORELLATO, L. P. C. A pesquisa em fenologia na América do Sul, com ênfase no Brasil, e suas perspectivas atuais. In: REGO, G. M.; NEGRELLE, R. B.; MORELLATO, L. P. C. (Org.). Fenologia como ferramenta para conservação e manejo de recursos vegetais. Curitiba: EMBRAPA, 2007. v. 1, p. 37-48.

MORELLATO, L. P. C. et al. Phenology of Atlantic Rain Forest trees: a comparative study. Biotropica, Belo Horizonte, v. 32, p. 811-823, 2000.

MOTA, F. S. Meteorologia agrícola. São Paulo: Nobel, 1976. 376 p.

ORTOLONI, A. A.; CAMARGO, M. B. P. Influência dos Fatores Climáticos na Produção. In: CASTRO, P. R. C. Ecofisologia da produção agrícola. Piracicaba: Associação Brasileira para Pesquisa da Potassa e do Fosfato, 1987.

PASCALE, A. J.; DAMARIO, E. A. Climatologia agricola y agroclimatologia. Buenos Aireas: EFA, 2004. 550 p.

PIRANI, F. R. et al. Fenologia de uma comunidade arbórea em cerrado sentido restrito, Barra do Garças, MT, Brasil. Acta Botânica Brasílica, Belo Horizonte, v. 23, n. 4, p. 1096-1109, 2009.

REYS, P. et al. Fenologia reprodutiva e disponibilidade de frutos de espécies arbóreas em mata ciliar no rio Formoso, Mato Grosso do Sul. Biota Neotropica, São Paulo, v. 5, n. 2, p. 309-318, 2005. 
REITZ, R; KLEIN, R. M; REIS, A. Projeto madeira do Rio Grande do Sul. Porto Alegre: Secretaria da Agricultura e de Abastecimento, 1988. 524 p.

TAIZ, L.; ZEIGER, E. Fisiologia Vegetal. Porto Alegre: Artmed, 2013. 4. ed. 820 p.

TALORA, D. C.; MORELLATO, L. P. C. Fenologia de espécies arbóreas em floresta de planície litorânea do sudeste do Brasil. Revista Brasileira de Botânica, São Paulo, v. 23, p. 13-26, 2000. 